\title{
Zaman Serisi Tahmin Probleminin İmmün Plazma Programlama Kullanılarak Çözülmesi
}

\author{
Sibel Arslan* \\ 1* Sivas Cumhuriyet Üniversitesi, Teknoloji Fakültesi, Sivas, Türkiye, (ORCID: 0000-0003-3626-553X), sibelarslan@cumhuriyet.edu.tr
}

(International Symposium on Multidisciplinary Studies and Innovative Technologies (ISMSIT) 2021 - 21-23 October 2021)

(DOI: 10.31590/ejosat.1010078)

\begin{abstract}
ATIF/REFERENCE: Arslan, S., Zaman Serisi Tahmin Probleminin İmmün Plazma Programlama Kullanılarak Çözülmesi. (2021). Avrupa Bilim ve Teknoloji Dergisi, (29), 219-224.

$\ddot{O} z$

Otomatik programlama, bir sistemde girdi ve çıktı değişkenleri arasındaki ilişkiyi model çıkararak açıklamaya çalışan bir makine öğrenmesi yaklaşımıdır. Zaman içerisinde sembolik regresyon, kümeleme, sınıflandırma, görüntü işleme, devre tasarımı, yol planlama, tahmin gibi birçok mühendislik problemlerini çözmeyi amaçlayan otomatik programlama yöntemleri geliştirilmiştir. Otomatik programlama yöntemlerinden birçoğu doğadan esinlenmektedir. Hızlı yayılan yeni Coronavirüs (COVID-19) salgınıyla mücadele edebilmek için farklı tedavi yöntemleri denenmektedir. İmmün plazma tedavisi, geçmişte birçok farklı salgında ve son olarak COVID19'da etkili olduğu gösterilmiş tıbbi bir tedavi yöntemidir. İmmün plazma tedavi yaklaşımının uygulama aşamalarına dayanan İmmün Plazma Algoritması (Immune Plasma Algorithm, IPA) kısa süre önce önerilmiş bir meta-sezgisel algoritmadır. IPA, 2020 yılında tanıtılmış yeni bir algoritma olmasına rağmen farklı problemleri çözmek için çeşitli alanlarda uygulanmıştır. Bu çalışmada, IPA algoritmasını temel alan İmmün Plazma Programlama (Immune Plasma Programming, IPP) bir otomatik programlama yöntemi olarak tanıtılmıştır. IPP algoritmasının genel işleyişi IPA'nın aşamalarına benzerdir. Çözümlerin temsili ve iyileştirme mekanizması IPP'nin temel farklarıdır. IPA çözümleri sabit boyutlu diziler şeklinde ifade ederken, IPP çözümleri farklı derinliklere sahip olabilen parçalı ağaçlar olarak ifade eder. Ağaçların en küçük birimi düğümlerle temsil edilir. Düğümler, problemler için özel tanımlanan terminal kümesinden (x, y gibi değişkenler ve sabitler) ve fonksiyon kümesinden (aritmetik operatörler, mantıksal fonksiyonlar, matematiksel fonksiyonlar) seçilirler. Bu düğümlerin birleşimi ile çözümleri temsil eden ağaçlar oluşturulur. Çözümlerin iyileştirme mekanizması olarak Yapay Arı Koloni Programlama'da (Artificial Bee Colony Programming, ABCP) kullanılan bilgi paylaşım mekanizması IPP'ye uyarlanmıştır. Önerilen algoritmanın performansı, literatürde yaygın olarak kullanılan Box-Jenkins zaman serisi kullanılarak incelenmiştir. Çıkarılan modeller, en çok kullanılan otomatik programlama yöntemi ABCP ve Yapay Sinir Ağı modelleri ile kıyaslanmıştır. Sonuçlar, IPP’nin zaman serileri tahmin problemlerinde başarıyla kullanabileceğini göstermiştir.
\end{abstract}

Anahtar Kelimeler: Otomatik Programlama Yöntemleri, İmmün Plazma Algoritması, İmmün Plazma Programlama, Zaman Serileri Tahmini, Plazma Tedavisi.

\section{Solving the Problem of Time Series Prediction Using Immune Plasma Programming}

\begin{abstract}
Automatic programming is a machine learning approach that attempts to explain the relationship between input and output variables in a system by extracting a model. Over time, automatic programming methods have been developed that aim to solve many engineering problems, such as symbolic regression, clustering, classification, image processing, circuit design, path planning, prediction. Most of the automatic programming methods are inspired by nature. To combat the rapidly spreading new coronavirus pandemic (COVID-19), various treatment methods are being tried. Immune plasma treatment is a medical treatment method that has proven to be effective in many different pandemics in the past and most recently in COVID-19. The Immune Plasma Algorithm (IPA) is a recently proposed meta-heuristic algorithm based on the implementation steps of the immune plasma treatment approach. Although IPA is a new algorithm, introduced in 2020, it has already been used in various fields to solve different problems. In this paper, the Immune Plasma Programming (IPP) automatic programming method based on IPA algorithm is presented for the first time. The general procedure of the IPP algorithm is similar to the stages of IPA. The representation of the solutions and the improvement mechanism are the main differences between the two algorithms. IPA expresses the solutions as fixed size arrays, while IPP represents the solutions as fragmented trees that can have different depths. The smallest unit of the trees is represented by nodes. The nodes are selected from a set of terminals (variables and constants such as $\mathrm{x}, \mathrm{y}$ ) and a set of functions (arithmetic operators, logical functions, mathematical functions)
\end{abstract}

* Sorumlu Yazar: $\underline{\operatorname{xxxx} @, x x x . x x . x x}$ 
defined for the problems. Solution trees are created by combining these nodes. As the improvement mechanism of the solutions, the information sharing mechanism used in Artificial Bee Colony Programming (ABCP) was adapted to IPP. The performance of the algorithm was evaluated using the Box-Jenkins time series, which is widely used in the literature. The extracted models were compared with the most commonly used automatic programming method ABCP and Artificial Neural Network (ANN) models. The results showed that IPP can be successfully applied to time series prediction problems.

Keywords: Automatic Programming Methods, Immune Plasma Algorithm, Immune Plasma Programming, Time Series Prediction, Plasma Treatment.

\section{Giriş}

Otomatik programlama, bir görevi yerine getirmek için gerekli bilgileri kullanarak otomatik program kodunu üreten bir bilgisayar programlama tekniğidir (Biermann, 1985). Literatürde Genetik Programlama (Genetic Programming, GP) (Koza, 1992), Karınca Programlama (Ant Programming, AP) (Roux ve Fonlupt, 2000), ABCP (Karaboğa vd., 2012), Yapay Bağışıklık Sistemi Programlama (Artificial Immune System Programming, AISP) (Johnson, 2003), Biyocoğrafya Tabanlı Programlama (Biogeography Based Programming, BBP) (Golofshani, 2015) gibi birçok otomatik programlama yöntemi bulunmaktadır. $\mathrm{Bu}$ yöntemlerin sembolik regresyon, öznitelik seçimi, sınıflandırma, rota bulma, zaman serileri tahmini gibi birçok karmaşık problemin çözümünde kullanıldığı ve oldukça iyi sonuçlar elde ettiği görülmektedir (Karaboğa vd., 2012; Arslan vd., 2019; Sotto vd. 2016; Cano ve Krawczyk, 2019; Chen vd.,2004). Bu problemlerden zaman serileri periyodik zaman aralıklarında gözlem değerlerinin ifade edildiği diziler olarak tanımlanmaktadır. Bir zaman serisinin belirli bir andaki gözlem değeri daha önceki gözlemlerin değerlerine bağlıdır. Günümüzde iktisat, işletme, mühendislik gibi birçok multidisipliner alanda zaman serileri analizi yapılmaktadır (Akdi, 2003).

Zaman seri modelleri üç farklı sınıfta kategorize edilir: doğrusal modeller, doğrusal olmayan modeller ve her iki modelin kombinasyonunu içeren hibrit modeller (Li ve Tanaka, 2021). Serilerin giriș ve çıkış gözlem değerleri dikkate alınarak bu değerler arasında en uygun ilişkinin fonksiyonel olarak belirlenmesi model çıkarımı için gereklidir. Özellikle doğrusal olmayan ve hibrit modellerde ilgili parametrelerin, değişkenlerin en iyi kombinasyonunun belirlenmesi zaman serileri tahmininde karşılaşılan temel bir problemdir. $\mathrm{Bu}$ çalışmada, bu problemle başa çıkabilmek için İmmün Plazma Algoritması (IPA)'nın otomatik programlama versiyonu İmmün Plazma Programlama (Immune Plasma Programming, IPP) tanıtılmıştır. IPP ile çıkarılan modeller ile sıkça kullanılan bir test problemi olan BoxJenkins zaman serisi tahmin edilmiş ve tahmin sonuçları sıkça kullanılan Yapay Arı Koloni Programlama (Artificial Bee Colony Programming, ABCP) ve Yapay Sinir Ağları (Artificial Neural Network, ANN) yöntemleri ile kıyaslanmıştır.

Makalede IPP'nin tanıtılmasına Bölüm 2'de; problem tanımı, kullanılan parametreler, simülasyon sonuçlarının sunulması ve tartışılması hakkında ayrıntılı bilgiye Bölüm 3'de; sonuçlar ve gelecekteki çalışmalara Bölüm 4'de yer verilmiştir.

\section{Materyal ve Metot}

$\mathrm{Bu}$ bölümde, bu çalışmada önerilen İmmün Plazma Programlama yöntemi anlatılmaktadır. Bu yöntem İmmün Plazma Algoritması'nı (Immune Plasma Algorithm, IPA) temel aldı ğı için önce bu algoritmadan bahsedilmiş, ardından IPP detaylı olarak anlatılmıştır.

\section{1. İmmün Plasma Algoritması (Immune Plasma Algorithm, IPA)}

Yarasalardan insanlara bulaşan yeni koronavirüs hastalığ1 (COVID-19), ilk olarak Aralık 2019'da Çin'in Vuhan Eyaleti'nde görülmüştür (Cascella vd., 2020). Virüsün 7 Ocak 2020'de tanımlanmasının ardından Dünya Sağlık Örgütü (World Health Organization, WHO) 11 Mart 2020'de COVID-19'u küresel bir salgın olarak ilan etmiştir (Huang vd., 2020). Bu salgınla mücadele edebilmek için farklı tedavi yöntemleri denenmektedir. İmmün plazma tedavisinde, daha önce iyileşen hastalardan alınan kanın bağışıklık cevabı üreten antikorlardan zengin kısmının hastaya nakledilerek hastanın iyileşmesi amaçlanır. Tedavinin iyileştirme başarısı H1N1 gribi, MERS, SARS, Ebola ve son olarak COVID-19 salgınlarında kanıtlanmıştır. Aslan ve Demirci, COVID-19 salgını ile birlikte uygulama sıklığı artan immün plazma tedavisi yaklaşımının temel özelliklerinden faydalanarak, IPA'yı tanıtmışlardır. Çalışmadaki deneylerde, IPA algoritması ile klasik, yüksek boyutlu test problemleri, karmaşık kıyaslama ve mühendislik problemleri çözülmüştür. Algoritma Genetik Algoritma (Genetic Algorithm, GA), Parçacık Sürü Optimizasyonu (Particle Swarm Optimization, PSO), Diferansiyel Gelişim (Differential Evolution, DE), Yapay Arı Kolonisi (Artificial Bee Colony, ABC) gibi birçok iyi bilinen meta sezgisel algoritma karşısında başarılı sonuçlar üretmiştir (Aslan ve Demirci, 2020). Bu çalışmada IPA'nın otomatik programlama versiyonu olarak IPP yöntemi önerilmiş ve zaman serisi tahmin probleminde bilinen mevcut yöntemlere göre performans değerlendirilmiştir.

IPA'da, immün plazma tedavisinin uygulama aşamalarını bir meta-sezgisel algoritmaya uyarlanarak algoritmanın araştırma ve çözümleri geliştirme kabiliyetini arttırmak hedeflenmiştir. Algoritma tasarımında, enfeksiyonun bireyler arasında yayılması algoritmanın araştırma; plazma transferi çözümleri geliştirme aşamalarına benzetilmiştir. IPA, popülasyon temelli bir algoritmadır. Algoritmada popülasyondaki her bir birey problemin olası çözümünü, bireylerin ürettiği antikor miktarı çözümün kalitesini temsil eder. Bir bireyin ürettiği antikor miktarı ne kadar yüksekse çözümün kalitesi o kadar fazladır. Başka bir deyişle, amaç fonksiyonu o kadar iyi bir çözüm elde etmiştir (Aslan ve Demirci, 2020). IPA'da problemin olası çözümleri, karar değişkenleri için önerilen değerleri taşıyan ve araştırma boyunca boyutu sabit kalan dizilerle temsil edilir.

IPA'nın temel algoritmik yapısı ve aşamaları aşağıda verilmiştir.

\section{Başlangıç aşaması}

\section{REPEAT}

Enfeksiyonun yayılma fazı

Plazma transferi fazı

Donörlerin bağışıklık hafızasının kontrolü fazı

UNTIL (durdurma kriteri sağlanıncaya kadar)

Başlangıç aşaması: Bu aşamada her bir birey için başlangıç çözümleri belirlenir. $D$ boyutlu bir problem için $x_{k}$ çözümünün j'nci boyut karar değişkeni için ataması Eşitlik (1) ile yapılır. 


$$
x_{k j}=x_{j}^{\min }+\operatorname{rand}(0,1)\left(x_{j}^{\max }-x_{j}^{\min }\right)
$$

Burada $x_{j}^{\max }$ ve $x_{j}^{\text {min }}$ sirasiyla j'inci boyutun alabileceği en büyük ve en küçük değerleri ve rand $(0,1) 0$ ile 1 arasında normal dağılıma uygun olarak rastgele üretilmiş sayıyı göstermektedir. Oluşturulan bu çözümlerin bağışıklık cevabı/kalitesi amaç fonksiyonu ile değerlendirilmektedir.

Enfeksiyonun yayılma fazı: IPA'da, enfeksiyonun bireyler arasında yayılması algoritmanın araştırma alanını arttırmak için kullanılmıştır. Hasta bireyler, enfeksiyon etkenini doğrudan veya dolaylı yolla bulaştırabilir. Enfekte olmuş bireyin bağışıklık sistemi, o enfeksiyona karşı korumak için özel bir bağışıklık cevabı geliştirir. Popülasyonda enfeksiyonun bireyler arasında yayılması Eşitlik (2) ile gerçekleştirilir.

$$
x_{k j}^{i n f}=x_{k j}+\operatorname{rand}(-1,1)\left(x_{k j}-x_{m j}\right)
$$

$x_{k}$ bireyinin enfeksiyon öncesinde $j$ 'nci boyutunun değeri $x_{k j}$ ile gösteriliriken; $x_{k j}^{i n f}$, enfekte olan $x_{k}$ bireyinin $j$ 'nci boyutunu ifade etmektedir. $x_{m j}, x_{k}$ bireyi dişında popülasyondan rastgele seçilen $x_{m}$ bireyinin j'nci boyutunun değeridir. $\operatorname{rand}(-1,1)$ ise -1 ile 1 aralığında rastgele üretilen bir sayıdır. Enfeksiyonun yayılmasından sonra, enfekte olmuş birey $\left(x_{k}^{\text {inf }}\right)$ ile enfeksiyon öncesindeki birey $\left(x_{k}\right)$ arasında bağışıklık cevapları dikkate alınarak aç gözlü seleksiyon uygulanmaktadır. Böylelikle bağışıklık cevabı yüksek olan birey popülasyonda korunmaktadır. (Aslan ve Demirci, 2021). Bu fazda, popülasyondaki her bir birey enfekte edilerek bağışık cevabının iyileştirilmesi amaçlanır.

Plazma transferi fazı: Enfeksiyonun yayılma fazından sonra

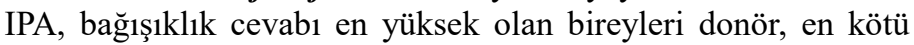
bireyleri alıcı olarak tayin eder. Algoritma başlangıcında, donör bireylerin sayısı ( $N o D$, Number of Donors), alıcı bireylerin sayıs1 (NoR, Number of Receivers) sabit olarak belirlenir. Böylelikle bağışıklık cevabı en iyi toplam $N o D$ bireyi donör, bağışıklık cevabı en kötü toplam $N o R$ bireyi alıcı seçilmiş olunur. Bu fazda her bir alıcı bireye, toplam $N o D$ donör arasından rasgele seçilen bir donör ile plazma transferi gerçekleştirilir. $k$ indisi $\{1, \ldots, N o R\}$ kümesinden sirayla seçilen bir alıcı olmak üzere, $x_{k}^{r c v}$ alıc1 bireyine $N o D$ donör arasından rastgele seçilen $x_{m}^{d n r}$ donörüne ait plazmanın transferi Eşitlik (3) ile ifade edilmiştir.

$$
x_{k j}^{r c v-p}=x_{k j}^{r c v}+\operatorname{rand}(-1,1)\left(x_{k j}^{r c v}-x_{m j}^{d n r}\right)
$$

Burada, $x_{k}^{r c v}$ bireyinin plazma transferi öncesi $j$ 'inci boyutunun değeri $x_{k j}^{r c v}, x_{m}^{d n r}$ donörünün $j$ 'inci boyutunun değeri $x_{m j}^{d n r}$ ile ifade edilmektedir. İlk doz plazma transferinden sonra, plazma transfer edilmiş birey $\left(x_{k}^{r c v-p}\right)$ ile donörü $\left(x_{m}^{d n r}\right)$ arasında açgözlü seçim uygulanır. Eğer $x_{k}^{r c v-p}$, nin bağışıklık cevabı, $x_{m}^{d n r}$, den daha iyiyse transfer edilmemiş bireyin $\left(x_{k}^{r c v}\right)$ yerine transfer edilmiş birey $x_{k}^{r c v-p}$ geçirilir ve bir doz daha plazma transferi gerçekleştirilir (Aslan ve Demirci, 2020). Aksi durumda bireye plazma transferi yapıldığı için $x_{k}^{r c v}$ yerine donörü $x_{m}^{d n r}$ geçirilir ve transfer sonlandırılır. İkinci, üçüncü... n'inci doz plazma transferi de Eşitlik (3) ile gerçekleştirilir. Ancak bu transferler sonras1, transfer tedavisinin sonlandirma karar1 $x_{k}^{r c v-p}$ ile $x_{k}^{r c v}$ arasında açgözlü seçim ile verilir. Eğer $x_{k}^{r c v-p}$ bireyinin bağışıklık cevabı $x_{k}^{r c v}$ bireyinin bağışıklık cevabında daha kötü olursa plazma tedavisi tamamlanır. Diğer durumda $x_{k}^{r c v}$ yerine $x_{k}^{r c v-p}$ bireyi geçirilir ve bir doz daha plazma transferi uygulanır.
Donörlerin bağışıklık hafizasının kontrolü fazı: Popülasyonda donör olarak seçilen bireylerin bir enfeksiyona karşı verdiği bağışıklık cevabı zamanla değiş̧ebilir. Donörlerin bağışıklık cevabının zamana bağlı değişimi, değerlendirme sayısının $\left(t_{c}\right)$ toplam değerlendirme sayısına $\left(t_{\max }\right)$ oranından faydalanılarak değerlendirilir. Eğer, toplam $N o D$ donörün her bir $x_{m}^{d n r}$ için belirlenen $\left(t_{c} / t_{\max }\right)$ değeri 0 ile 1 arasında rastgele belirlenen sayıdan küçük ise $x_{m}^{d n r}$ bireyi tamamen değiştirilir. Diğer durumda ise Eşitlik (4) kullanılarak $x_{m}^{d n r}$ bireyinin her $\mathrm{j}$ boyutu güncellenerek bağışıklık hafızası kontrol edilir (Aslan ve Demirci, 2020).

$$
x_{m j}^{d n r}=x_{m j}^{d n r}+\operatorname{rand}(-1,1) x_{m j}^{d n r}
$$

\section{2. İmmün Plazma Programlama (Immune Plasma Programming, IPP)}

IPP, IPA algoritmasına dayanan yüksek seviyeli otomatik programlama metodu olarak önerilmiştir. IPP algoritması için temel aşamalar IPA'nın aşamalarına benzerdir ve aynı anolojiyi kullanmaktadır. İki algoritma arasında en temel farklılık bireylerin temsilinde IPA çözümleri sabit boyutlu diziler şeklinde ifade ederken, IPP çözümleri parçalı ağaçlar olarak ifade eder. IPP'de her parçalı ağaç, sistemin bağımsız değişkenleri ile bağımlı değişkeni arasında en uygun fonksiyonel ilişkiyi belirlemeye çalışır. Ağaçların en küçük birimine düğüm denir. Düğümler, problemler için özel olarak tanımlanmış terminal kümesi ( $x, y$ gibi değişkenler ve sabitler) ve fonksiyon kümesi (aritmetik operatörler, mantıksal ve matematiksel fonksiyonlar) arasından seçilir. Şekil 1 IPP için örnek bir çözümü göstermektedir. Çözümün değişkenler arasındaki fonksiyonel ilişkisi ise Eşitlik (5) ile verilmiştir. Bu gösterimlerde bağımsız değişkenler $x_{1}, x_{2}$, bağımlı değişken $f\left(x_{1}, x_{2}\right)$ sembolleri ile temsil edilmiştir.

IPP algoritmasında, IPA'dan farklı olarak parçalı ağaçların üretilmesinde kullanılan "ramped half and half" metodu kullanılmıştır. "Ramped half and half" metodu, otomatik programlama yöntemlerinde çözümlerin üretilmesinde kullanılan yöntemlerdendir ve detaylarına (Koza, 1992)'dan ulaşılabilinir. IPA'da çözümlerin gösterimi sabit boyutlu dizilerle gerçekleştirildiği için algoritmada enfeksiyonun yayılma, plazma transferi ve donörlerin bağışıklık hafızasının kontrolü fazlarında kullanılan eşitlikler doğrudan kullanılamamaktadır. IPP'de yapılan diğer temel farklılık, iyileştirme mekanizması olarak adlandırılan ve bu fazlardaki eşitlikler yerine kullanılan mekanizma üzerindedir. İyileştirme mekanizması, ABCP'de kullanılan bilgi paylaşım mekanizmasının (Karaboğa vd., 2012) uyarlamasıdır. Bu mekanizma Şekil 2'de gösterilmiştir. Şekil 2a ve 2 b'de sırasıyla alıcı $\left(x_{k}^{r c v}\right)$ ve donör $\left(x_{m}^{d n r}\right)$ gösterilmiştir, donörden alınan bilgi (c)'de ve plazma transfer edilmiş birey aday çözüm ( $x_{k}^{r c v-p}$ )'de verilmiştir. Algoritmada, Eşitlik (2), (3) ve (4) yerine eşitliklerdeki ilgili bireyler iyileştirme mekanizmasında kullanılarak fazlar gerçekleştirilmiştir. 


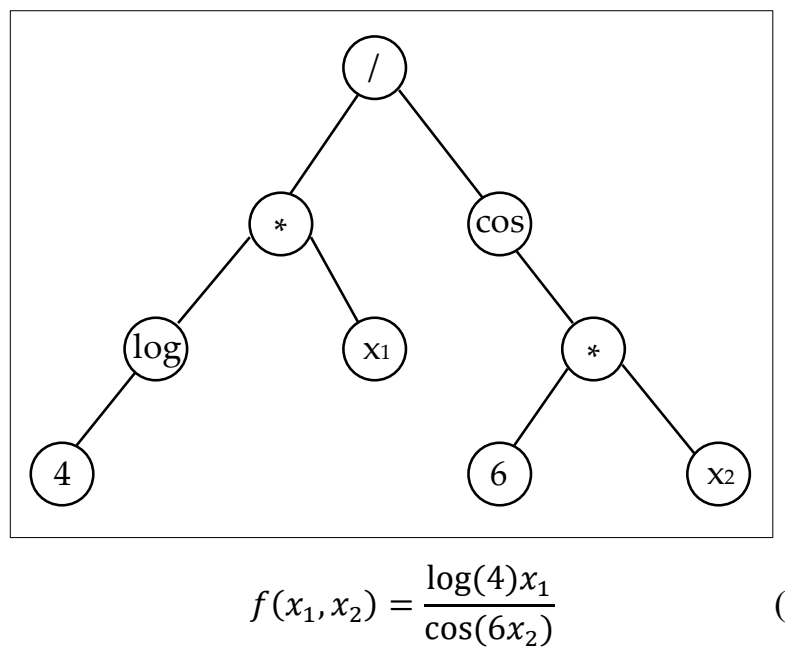

Şekil 1. IPP'de çözümlerin ă̆aç yapısı ile temsili

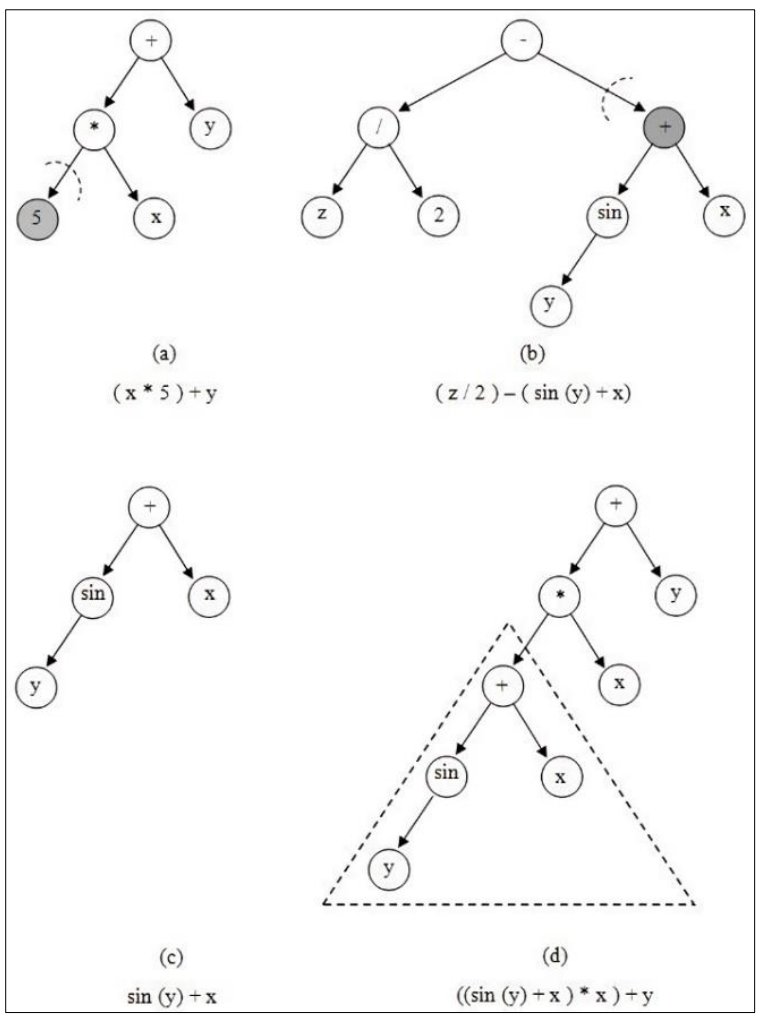

Şekil 2. IPP iyileştirme mekanizması

fonksiyonda bölen değeri 0'a eşitse, sonuca 1 değeri atanır, aksi takdirde normal bölme gerçekleştirilir. Bu problem için farklı donör sayıları ve alıcı sayıları ile yapılan deneylerde en başarılı donör/alıcı sayısı 1 olarak belirlenmiştir. Çalışma $30 \mathrm{kez}$ bağımsız koşturulmuştur. Koşmalarda (Görkemli vd., 2012)'da kullanılan amaç fonksiyonu Ortalama Hatanın Karesi (Mean Square Error, MSE) Eşitlik (6)'da verilmiştir. Burada $y_{\text {actual }}$ tahmin edilen çıkışın gerçek değerini, $y_{\text {pred }}$ çözümün ürettiği tahmin değerini temsil etmektedir.

$$
M S E=\frac{1}{N} \sum_{j=1}^{N}\left(y_{\text {actual }}-y_{\text {pred }}\right)^{2}
$$

\subsection{Simülasyon Sonuçları ve Tartışmalar}

Koşmalarda elde edilen modellerin ortalaması, standart sapması (Görkemli vd., 2012)'daki sonuçlar ile birlikte Tablo 2'de sunulmuştur. Tablo 2'deki sonuçlar değerlendirildiğinde IPP'nin eğitim verisinde $\mathrm{ABCP}$ ve YSA modelinden daha iyi olduğu görülmektedir. Bununla birlikte testte ABCP yöntemi en başarılı modeli çıkarmıştır. IPP için en iyi sonucu veren çözümün yakınsama grafikleri Şekil 3 ve Şekil 4'de sunulmuştur.

Şekil 3 ve Şekil 4'deki grafikler incelendiğinde hem eğitim ve hem test verisinde gerçek ve tahmini serinin birbiriyle oldukça uyumlu olduğu görülmektedir. 30 koşma sonucunda elde edilen en iyi modelin denklemi Eşitlik (7)'de verilmiştir. Karmaşık bir zaman serisi eğrisi için Eşitlik (7) analiz edildiğinde, ikinci dereceden nonlineer bir model olduğu ve özellikle eğitim verisi tahmininde oldukça başarılı olduğu değerlendirilmiştir.

$$
\begin{gathered}
(2 \mathrm{y}(t-1)-\mathrm{u}(t))\left(\mathrm{u}(t)-\mathrm{u}(t)^{2}+4.857\right) 0.06998 \\
+0.3229
\end{gathered}
$$


Tablo 1. Parametre Değerleri

\begin{tabular}{|c|c|c|c|}
\hline \multicolumn{2}{|l|}{ IPP } & \multicolumn{2}{|l|}{$\mathbf{A B C P}$} \\
\hline Parametre & Değer & Parametre & Değer \\
\hline Popülasyon büyüklüğ̈̈ & 300 & Koloni büyüklüğ̈̈ & 300 \\
\hline Değerlendirme saylst & 10,000 & Değerlendirme sayısı & 10,000 \\
\hline Maksimum ă̆aç derinliği & 4 & Maksimum ă̆aç derinliği & 4 \\
\hline Fonksiyon kümesi & $+,-, *, /, \mathrm{sqr}$ & Fonksiyon kümesi & $+,-,{ }^{*}, /, \mathrm{sqr}$ \\
\hline Donör Sayısı (NoD) & 1 & Limit & 300 \\
\hline Alıcı Saylsı (NoR) & 1 & & \\
\hline
\end{tabular}

Tablo 2. IPP'nin ABCP ve Yapay Sinir A $\breve{g}$ Modeli ile klyaslanması

\begin{tabular}{|c|c|c|c|c|c|c|}
\hline & \multicolumn{2}{|c|}{ IPP } & \multicolumn{2}{|c|}{$\begin{array}{c}\text { ABCP } \\
\text { (Görkemli vd., 2012) }\end{array}$} & \multicolumn{2}{|c|}{$\begin{array}{l}\text { Yapay Sinir Ă̆ Modeli } \\
\text { Görkemli vd., 2012) }\end{array}$} \\
\hline & Ĕ̆itim & Test & Ĕ̆itim & Test & Ĕ̆itim & Test \\
\hline Ortalama & 0,000391 & 0,002755 & 0.000576 & 0.000022 & 0.006626 & 0.010572 \\
\hline Standart Sapma & 0,000004 & 0,009493 & 0.002658 & 0.000360 & 0.000029 & 0.000711 \\
\hline En Iyi & 0,000383 & 0,002667 & - & & - & \\
\hline
\end{tabular}

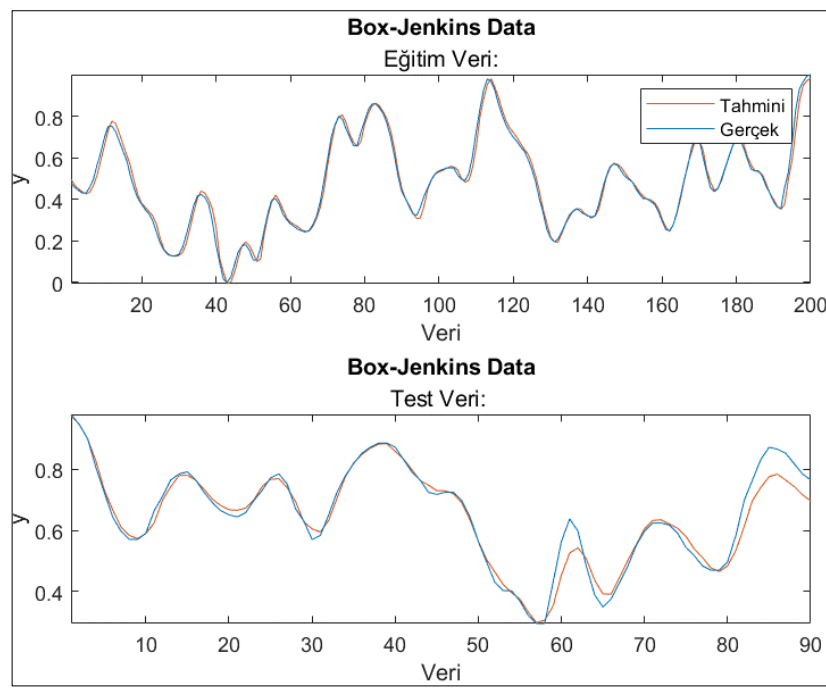

Şekil 3. Box-Jenkins zaman serisinde IPP en iyi modelinin yakınsama grafiğ $i$

\section{Sonuç}

Bu çalışmada İmmün Plazma Algoritması'nı temel alan yeni bir otomatik programlama yöntemi İmmün Plazma Programlama tanıtılmıştır. Yöntemin performansı, Box-Jenkins zaman serisi tahmin problemi üzerinde incelenmiştir. Deneyler, IPP ile çıkarılan modellerin tahmini çıkış değerlerinin gerçek değerlere oldukça yakın olduğunu göstermektedir. IPA'nın literatürde yaygın olarak kullanılan meta-sezgisel algoritmalara kıyasla, farklı türlerde optimizasyon problemleri için daha iyi çözümler elde etme yeteneğine sahip olduğu değerlendirilmiştir (Aslan ve Demirci, 2020). Bu yüzden, IPP'nin mevcut yöntemlere göre IPA gibi başarılı sonuçlar elde edeceği düşünülmekte ve IPP'nin literatürde yer alan birçok problemde kullanılabileceği düşünülmektedir. Gelecekteki çalışmalarda, farklı disiplinlerde problemler çözmek için IPP'nin kullanılması ve yeni düzenlemeler getirilerek IPP'nin performansının iyileştirilmesi üzerine çalışma yapılması planlanmaktadır.

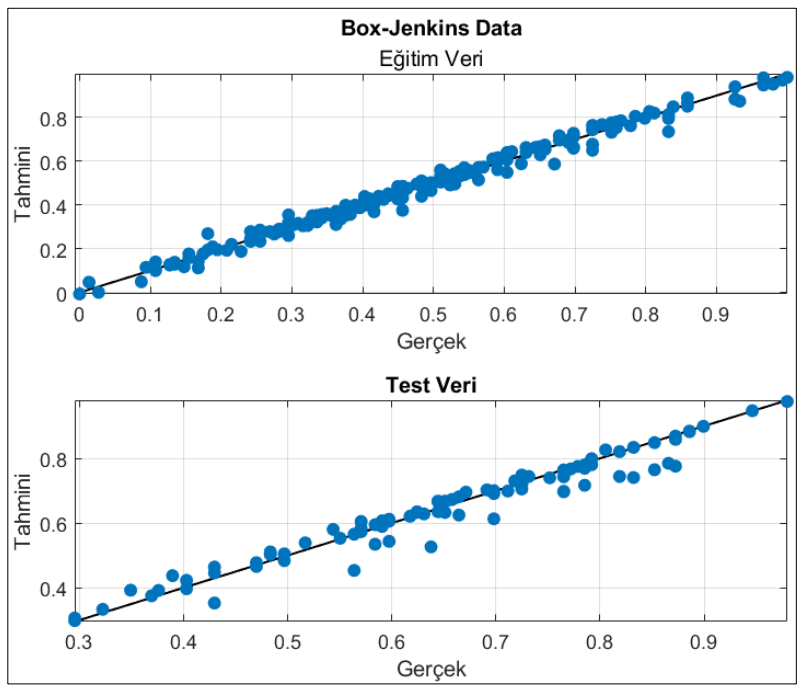

Şekil 4. Box-Jenkins zaman serisinde IPP en iyi modelinin tahmini ve gerçek veri noktaları arasındaki ilişki

\section{Teşekkür}

$\mathrm{Bu}$ çalışmanın yürütülmesinde destek veren kıymetli meslektaşlarım Dr. Öğretim Üyesi Fırat İsmailoğlu'na ve Begüm Yetişkin'e saygılarımı sunar, teşekkür ederim.

\section{Kaynakça}

Akdi, Y. (2003). Zaman Serileri Analizi.

Arslan, S., \& Öztürk, C., (2019). Multi Hive Artificial Bee Colony Programming for high dimensional symbolic regression with feature selection. APPLIED SOFT COMPUTING, vol.78, 515-527.

Aslan, S., \& Demirci, S. (2020). Immune Plasma Algorithm: A Novel Meta-Heuristic for Optimization Problems. IEEE Access, 8 , 220227-220245. https://doi.org/10.1109/access.2020.3043174

Aslan, S., \& Demirci, S. (2021). Performance Investigation of Parallel Immune Plasma Algorithm. Içinde 2021 International Conference on INnovations in Intelligent SysTems and Applications (INISTA). 2021 International Conference on INnovations in Intelligent SysTems and 
Applications (INISTA). IEEE. https://doi.org/10.1109/inista52262.2021.9548547

Biermann, A. W. (1985). Automatic programming: A tutorial on formal methodologies. Journal of Symbolic Computation, 1(2), 119-142. https://doi.org/10.1016/s07477171(85)80010-9

Box, G., Jenkins, G. (1970). Time Series Analysis: Forecasting and Control. Holden Day, San Francisco.

Cano, A., \& Krawczyk, B. (2019). Evolving rule-based classifiers with genetic programming on GPUs for drifting data streams. Pattern Recognition, 87, 248-268. https://doi.org/10.1016/j.patcog.2018.10.024

Cascella M., Rajnik M., Cuomo A., Dulebohn, S. C., \& Napoli R. D. (2020). Features, evaluation and treatment coronavirus (COVID-19). StatPearls [Internet], Stat Pearls Publishing.

Chen, Y., Yang, B., \& Dong, J. (2004). Evolving Flexible Neural Networks Using Ant Programming and PSO Algorithm. Içinde Advances in Neural Networks - ISNN 2004 (ss. 211216). Springer Berlin Heidelberg. https://doi.org/10.1007/978-3-540-28647-9_36

Golafshani, E. M. (2015). Introduction of Biogeography-Based Programming as a new algorithm for solving problems. Applied Mathematics and Computation, 270, 1-12. https://doi.org/10.1016/j.amc.2015.08.026

Görkemli, B., Öztürk, C., \& Karaboğa, D. (2012). Yapay Ar1 Kolonisi Programlama ile Sistem Modelleme. Otomatik Kontrol Türk Milli Komitesi 2012 Ulusal Toplantısı (TOK2012). 857-860. Niğde, Turkey.

Huang, C., Wang, Y., Li, X., Ren, L., Zhao, J., Hu, Y., Zhang, L., Fan, G., Xu, J., Gu, X., Cheng, Z., Yu, T., Xia, J., Wei, Y., Wu, W., Xie, X., Yin, W., Li, H., Liu, M., ... Cao, B. (2020). Clinical features of patients infected with 2019 novel coronavirus in Wuhan, China. The Lancet, 395(10223), $497-$ 506. https://doi.org/10.1016/s0140-6736(20)30183-5

Johnson, C. G. (2003). Artificial Immune System Programming for Symbolic Regression. Lecture Notes in Computer Science, 345-353. Springer Berlin Heidelberg. https://doi.org/10.1007/3-540-36599-0_32

Karaboğa, D., Öztürk, C., Karaboğa, N., \& Görkemli, B. (2012). Artificial bee colony programming for symbolic regression, Information Sciences, 209, 1-15.

Koza, J.R. (1992). Genetic Programming: On the Programming of Computers by Means of Natural Selection, Cambridge: MIT Press.

Li, Z. \& Tanaka, G. (2021). Multi-Reservoir Echo State Networks with Sequence Resampling for Nonlinear Time-Series Prediction. Neurocomputing.

Roux, O., Fonlupt, C. (2000). Ant programming: or how to use ants for automatic programming, in 2nd International Workshop on Ant Algorithms (ANTS'2000), 121-129. Brussels, Belgium.

Sotto, L. F. D. P., de Melo, V. V., \& Basgalupp, M. P. (2016). An improved $\lambda$-linear genetic programming evaluated in solving the Santa Fe ant trail problem. Proceedings of the 31st Annual ACM Symposium on Applied Computing. SAC 2016: Symposium on Applied Computing. https://doi.org/10.1145/2851613.2851669 